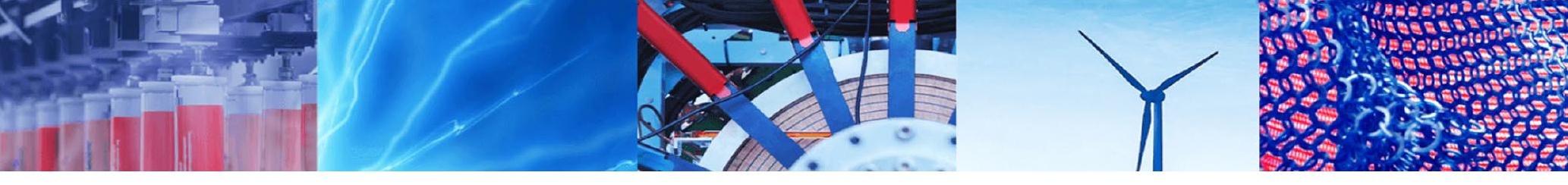

Research Article

\title{
Improvement of transient stability in microgrids using RSFCL with series active power filter
}

\author{
M. Uma Maheswara Rao' ${ }^{1}$ (I) K. Mercy Rosalina ${ }^{1}$
}

Received: 22 October 2019 / Accepted: 13 November 2019 / Published online: 18 November 2019

(c) Springer Nature Switzerland AG 2019

\begin{abstract}
Now a day's non-conventional energy sources like PV power and Wind power sources are well developed because conventional energy sources are reduced day by day and at the same time the population has been increased. These drawbacks can be overcome by developing the microgrids. In current trends, microgrid protection is a very challenging task. Due to the interconnection of several distributed generators, fault currents are produced. Resistive type superconducting fault current limiter is used for the protection of microgrids because its operating time is very less, it stops the abnormal currents with in the first cycle and continuity of supply is possible. But R-SFCL had some disadvantages, it is not compensated for the reactive power. Then voltage levels are not compensated, for that reason series active power filters are used along with R-SFCL. Here series active power filters are compensating the voltage magnitudes and reduce the harmonics and then transient stability is improved in the microgrids. This work is done using MATLAB/Simulink.
\end{abstract}

Keywords Resistive type superconducting fault current limiter - Matlab · Series active power filter · Circuit breaker . Distributed generation - Phase-locked loop circuits

$\begin{array}{ll}\text { Abbreviations } \\ \text { SAPF } & \text { Series active power filter } \\ \text { PLL } & \text { Phase-locked loop circuits } \\ \text { R-SFCL } & \text { Resistive type superconducting fault current } \\ & \text { limiter } \\ \text { DG } & \text { Distributed generation } \\ \text { CB } & \text { Circuit breaker }\end{array}$

\section{Introduction}

Nowadays the population has been increased and at the same time a bulk amount of electrical energy is required. But our conventional energy sources are limited, and they reduce day by day. For this reason, people look for nonconventional energy sources and in general solar and wind sources are majorly developed and fuel cell development is in the final stage. This secondary energy source having more advantages is free of cost, free from pollution and no need for input fuel. Here these secondary energy sources having a disadvantage like a continuity of supply becomes impossible, so these plants are called peak load plants. For this reason, integrate the distributed generation with the main grid by using a phase-locked loop circuit (PLL) [1]. Here synchronization process is very difficult and the same time due to the interconnection of the number of DGs, the short circuit currents will arise.

Up to now, circuit breakers are used for the protection of fault currents but at the time of fault condition, circuit breakers allow up to three cycles of fault currents due to which fault currents system face some damage [2]. At the time of the fault, breakers are opened with the help of overcurrent relay, so that the continuity of supply is not possible. These disadvantages can be overcome by using $\mathrm{R}-\mathrm{SFCL}$; it is a fast-operating device, it stops the fault currents for the first cycle and continuity of supply is possible;

M. Uma Maheswara Rao, umamaheswar9999@gmail.com; K. Mercy Rosalina, mercyroslink@gmail.com|'Department of Electrical \& Electronics Engineering, Vignan's Foundation for Science, Technology \& Research, Vadlamudi, Guntur, Andhra Pradesh 522213, India. 
[3]. Here R-SFCL material is made up of yttrium barium copper oxide (YBCO). During the normal working conditions, YBCO acts as a superconductor, under abnormal conditions YBCO metal is heated and increases the impedance due to which the increasing impedance fault currents are limited [4]. After clearing the fault, YBCO metal is cooled and it comes to the superconducting state [5].

Here R-SFCL limits only fault currents, and does not compensate the reactive components due to the presence of reactive components, eventually harmonics is presented and the voltage levels are not compensated. These voltage levels are compensated by using SAPF along with R-SFCL's and then the system comes into the transient stability [6]. Having one hysteresis controller with SAPF, the voltage levels are compensated. This microgrid system having three DG'S which are PV power, Fuel cells, and Wind power. These three DGs are synchronized with the main grid using PLL circuits. In this microgrid, three DG'S are protected from various types of faults using R-SFCL along with SAPF. The following results are good.

The main objective of this work is to improve the transient stability in microgrids. Up to now, literature discussed limiting the fault currents using R-SFCL, they are not discussed about Reactive power and voltage compensation.

The novelty of this work is to compensate the voltage levels for that reason, SAPF is used along with R-SFCL then fault currents are limited, the reactive power is compensated, voltage harmonics are reduced that means voltage levels are compensated. Finally, the system comes into the transient stability.

\subsection{Literature review}

Zheng et al. [7] have offered an R-SFCL for the protection of microgrids. But they are concentrated only on fault current limitations, not concentrate on reactive power and harmonics.

Lim et al. [8] have offered R-SFCL coordination with overcurrent relay, in this work overcurrent relay is used as voltage component and reduced the relay tripping time here they concentrate only relay time limiting, not concentrating on the stability.

Chen et al. [9] have offered coordination of SFCL with SMES through wireless communication, in this work they did not discuss faults and fault currents. So due to the fault currents system is not in stable condition.

Lan et al. [10] have offered a Location and size determination method of SFCLs in multi-terminal VSC-HVDC using iterative current reduction ranking, Here they didn't discuss voltage levels and stability.

Beyond that literature R-SFCL limits only fault currents, not compensate the reactive components, due to the presence of reactive components harmonics is presented finally voltage levels are not compensated. These voltage levels are compensated by using Series Active Power Filter (SAPF) with R-SFCL's then the system comes into the transient stability

\section{SFCL resistive type}

As compare to circuit breakers, R-SFCL gives much better performance it is a fast-operating device it stops the fault currents in the first cycle and continuity of supply is possible. Here R-SFCL material is made with yttrium barium copper oxide (YBCO) [11]. At normal working conditions, YBCO acts as a superconductor, during abnormal conditions YBCO material is heated and increases the impedance because of increasing impedance, fault currents are minimized [4]. After clearing the fault again YBCO metal is cooled and it comes to the normal resistance state. This technology is mainly used in South Korea, China and Japan countries.

Mathematical modelling of the SFCL resistive type is given below equation.

$$
R(t)= \begin{cases}0 & t<t_{0} \\ R_{S F C L}\left[1-\exp \left(-\frac{t-t_{0}}{\tau}\right)\right]^{1 / 2} & t_{0} \leq t<t_{1} \\ a_{1}\left(t-t_{1}\right)+b_{1} & t_{1} \leq t<t_{2} \\ a_{2}\left(t-t_{2}\right)+b_{2} & t_{2} \leq t\end{cases}
$$

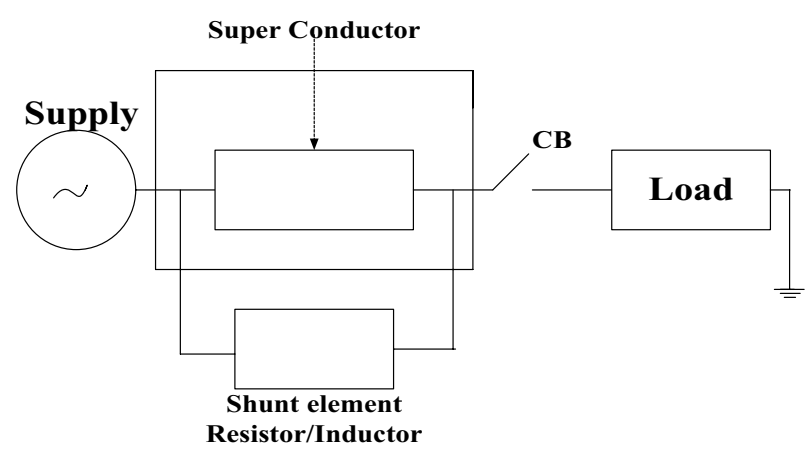

Fig. 1 Resistive type SFCL

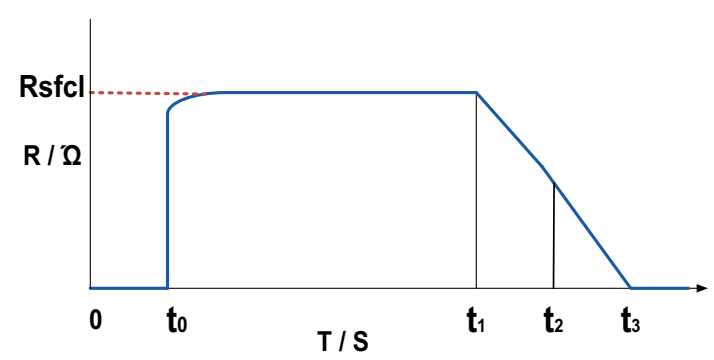

Fig. 2 Regaining and quench features of R-SFCL 
where $R_{S F C L}$ is Nominal resistance of resistive type SFCL in ohms, $\tau$ is time constant, $\left(t_{0}, t_{1}\right.$ and $\left.t_{2}\right)$ be the time intermissions in seconds and $\left(a_{1}, a_{2}, b_{1}\right.$ and $\left.b_{2}\right)$ be the different factors.

Here one shunt element is connected to a superconductor, this shunt branch is used to protect the superconductor from bulk voltages and hot spots. Compared to other SFCL', R-SFCL is less weight, occupies less space, fastest operation and less maintenance cost. Figure 1 expressions the resistive type SFCL.

Figure 2 specifies the regaining and quench features of R-SFCL on dissimilar time intervals, at each intermission $\mathrm{R}-\mathrm{SFCL}$ resistance is different.

Where $\left(t_{0}, t_{1}\right.$ and $\left.t_{2}\right)$ be the time intermissions in seconds, scale on $\mathrm{X}$-axis time in seconds and $\mathrm{Y}$-axis resistance in ohms and CB is Circuit breaker.

\section{Series active type power filters}

R-SFCL limits only fault currents, not compensate the reactive components, due to the presence of reactive components harmonics are presented finally voltage levels are not compensated. These voltage levels are compensated by using Series Active Power Filter (SAPF) along with R-SFCL's then the system comes into stability

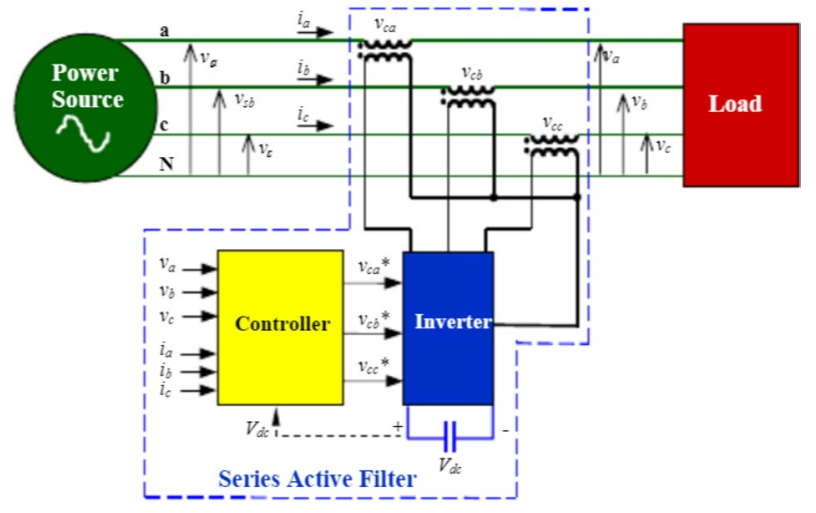

Fig. 3 Series active type power filter

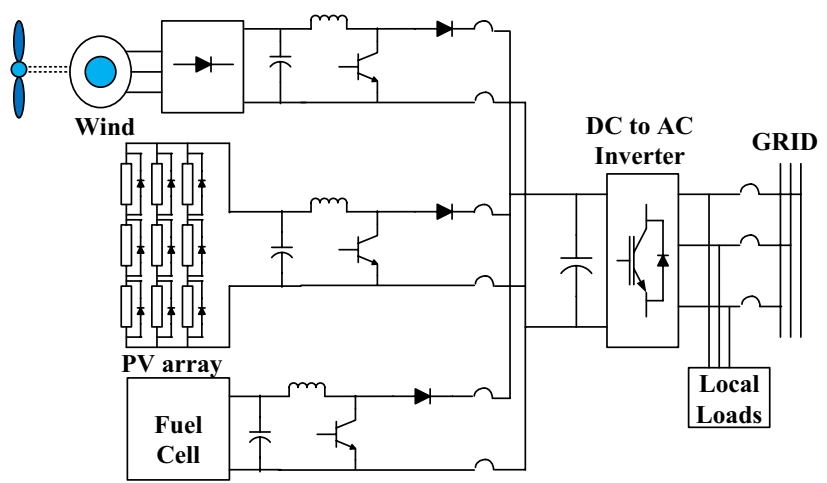

Fig. 4 Hybrid power system
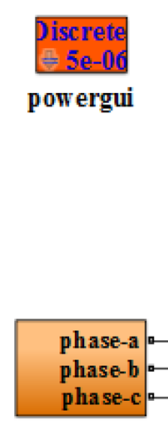

Fuel cell

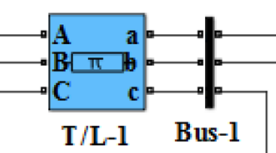

T/L-1 Bus-1

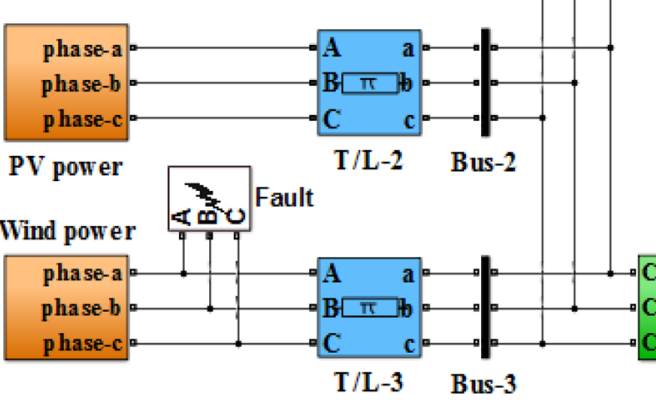

T/L-3 Bus-3

Fig. 5 Schematic diagram of the microgrid system model 
[12]. Here SAPF consists of one reference voltage source, inverter, injection transformer, electrolytic capacitors and hysteresis controller.

Here SAPF is connected in series with the transmission line through injection transformer, hysteresis controller is comparing the transmission line voltages with reference voltages [13]. whenever the operating voltage value of transmission line is decreases as compared with pre-setting voltage value. Then the hysteresis controller sends a signal to the inverter then inverter firing angles are changed and corresponding voltage is sent to the transmission line with the help of injection transformer. Inverter output-controlled voltage equation is

$v_{c}=v_{d c}(2 v-1)$

where $V_{c}$ is controlled voltage from the inverter output in volts, $V_{d c}$ is Input voltage of the inverter in volts and $V$ is [0 or 1] Input values of IGBT's

SAPF has reduces the voltage harmonics and it reduces the voltage sag and swell. Finally, power transfer capability increased then the microgrid stability is improved. Hysteresis controller operation is depending on the below equation.

$v_{I N J}=v_{L}-v_{S}$

$V_{\text {INJ }}$ is Injected voltage in volts, $V_{L}$ is Voltage at load side in volts and $V_{S}$ is Voltage at the source side in volts

Figure 3 specifies the block diagram of the SAPF.

\section{Microgrid system model}

The proposed microgrid consists of three DGs, Fuel cell, Wind power and PV power. These three DG's are synchronized with the conventional grid. Here three, 3-phase loads are connected raring of these loads are $150+\mathrm{j} 25(\mathrm{kVA})$ at load-1, 450+j30 (kVA) at load-2 and 200+j20 (kVA) at load-3. In this system transmission point voltage is $10.5(\mathrm{kV})$ and the distribution level voltage is 400 (V) 50 (HZ) AC. At the time of normal operating conditions fuel cell delivers $10(\mathrm{~kW})$ power, windmill delivers $150(\mathrm{~kW})$ power and $\mathrm{P}-\mathrm{V}$ module delivers $250(\mathrm{~kW})$ power to the load as shown in Fig. 4.

\section{Simulink model}

This projected microgrid system is established using MAT$L A B /$ Simulink, these software benefits equate to EMTP and PSPICE. Here one LLL-G fault is created nearer the wind power station. R-SFCL and SAPF are connected in the microgrid system are shown in Fig. 5. Figure 6 signifies the

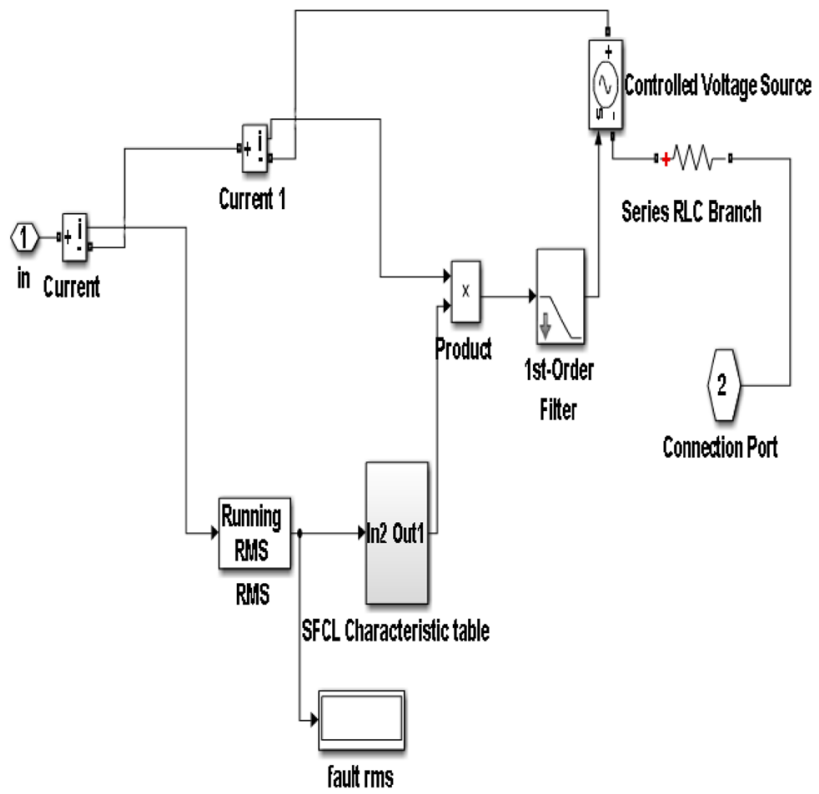

Fig. 6 Schematic diagram of R-SFCL for single phase

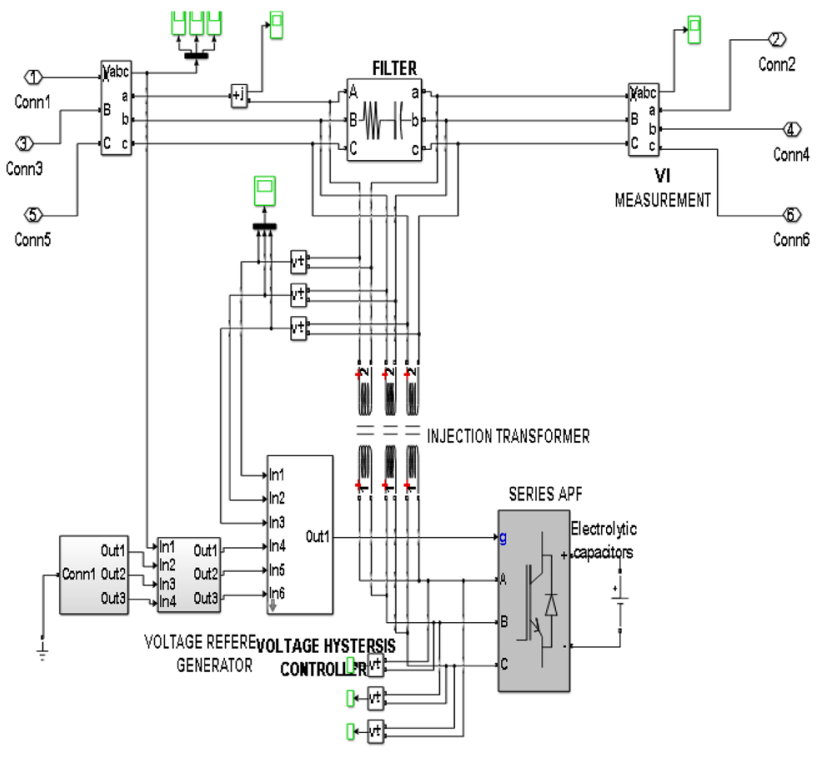

Fig. 7 Schematic diagram of SAPF for three-phase

Simulink diagram of R-SFCL and Fig. 7 signify the Simulink diagram of SAPF.

\section{Results and discussion}

From the main simulation, one LLL-G fault created at wind DG, that fault time is $0.08-0.12 \mathrm{~s}$. At the time of fault duration currents are increased up to 1217 (AMPS), After that $\mathrm{R}-\mathrm{SFCL}$ is decreased that fault currents to 830 (AMPS). Again, SAPF is limited that fault currents to 683 (AMPS) as specified in the Fig. $8 \mathrm{a}-\mathrm{c}$. 
Fig. 8 a Fault currents near the fault. b Fault currents near the fault with R-SFCL. c Fault currents near the fault with R-SFCL and SAPF (a)

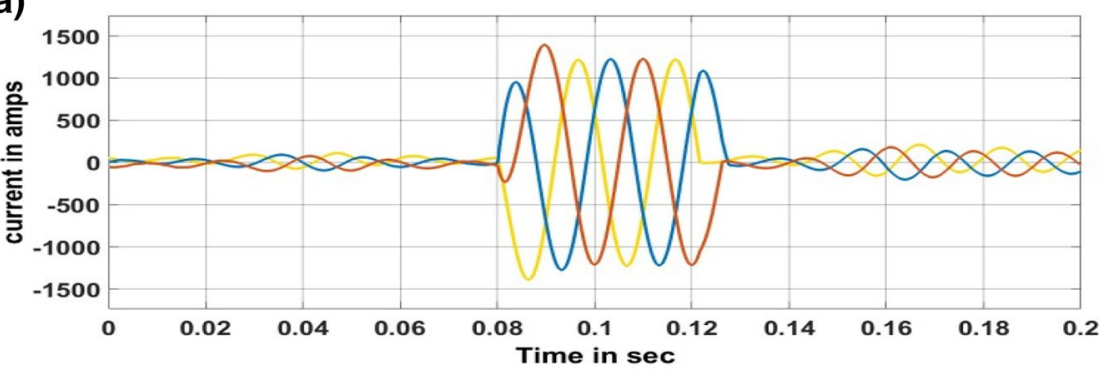

(b)

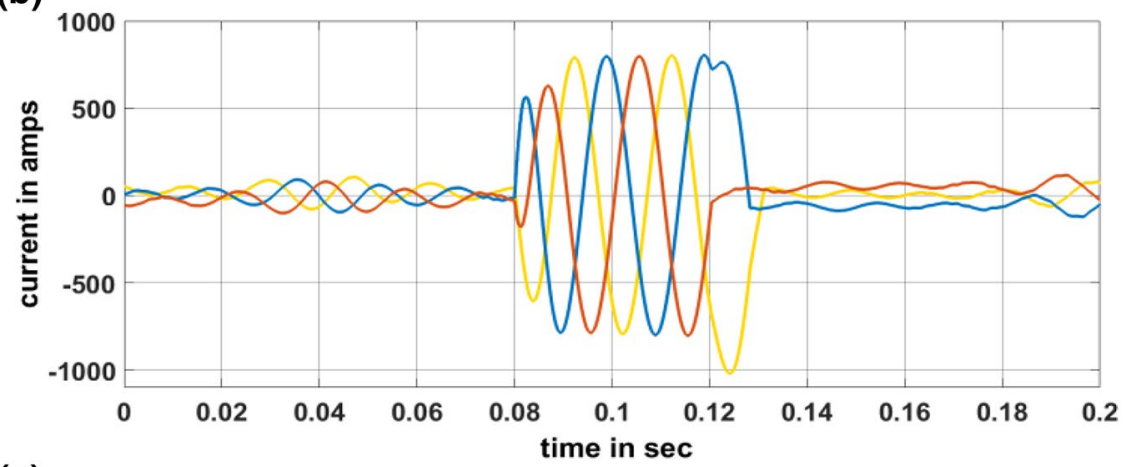

(c)

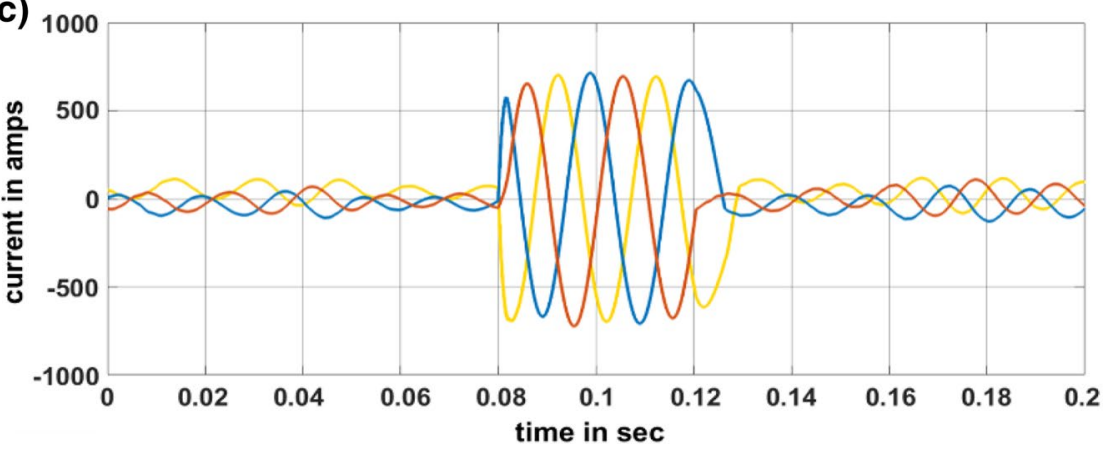

Here one LLL-G fault created at wind DG, that fault time is $0.08-0.12 \mathrm{~s}$. At the time of fault duration voltage levels reduced. R-SFCL not compensated the voltage levels exactly because, due to the presence of reactive power and harmonics. Here SAPF reduces the harmonic content and compensates the reactive power then voltage stability is improved as specified in Fig. 9a-c. 
(a)

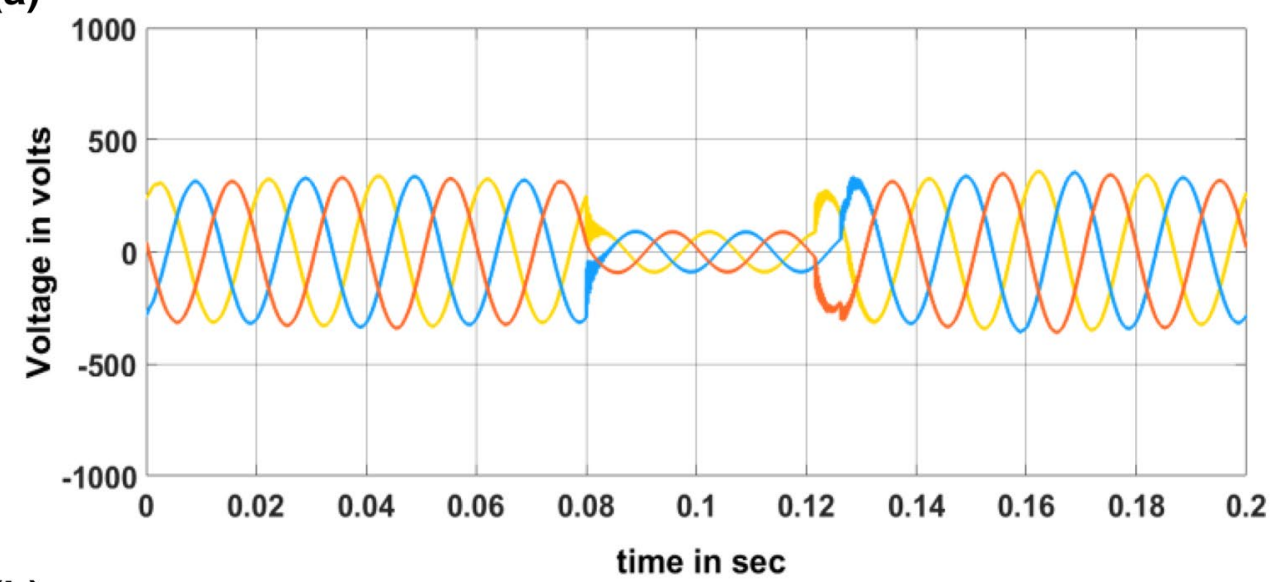

(b)
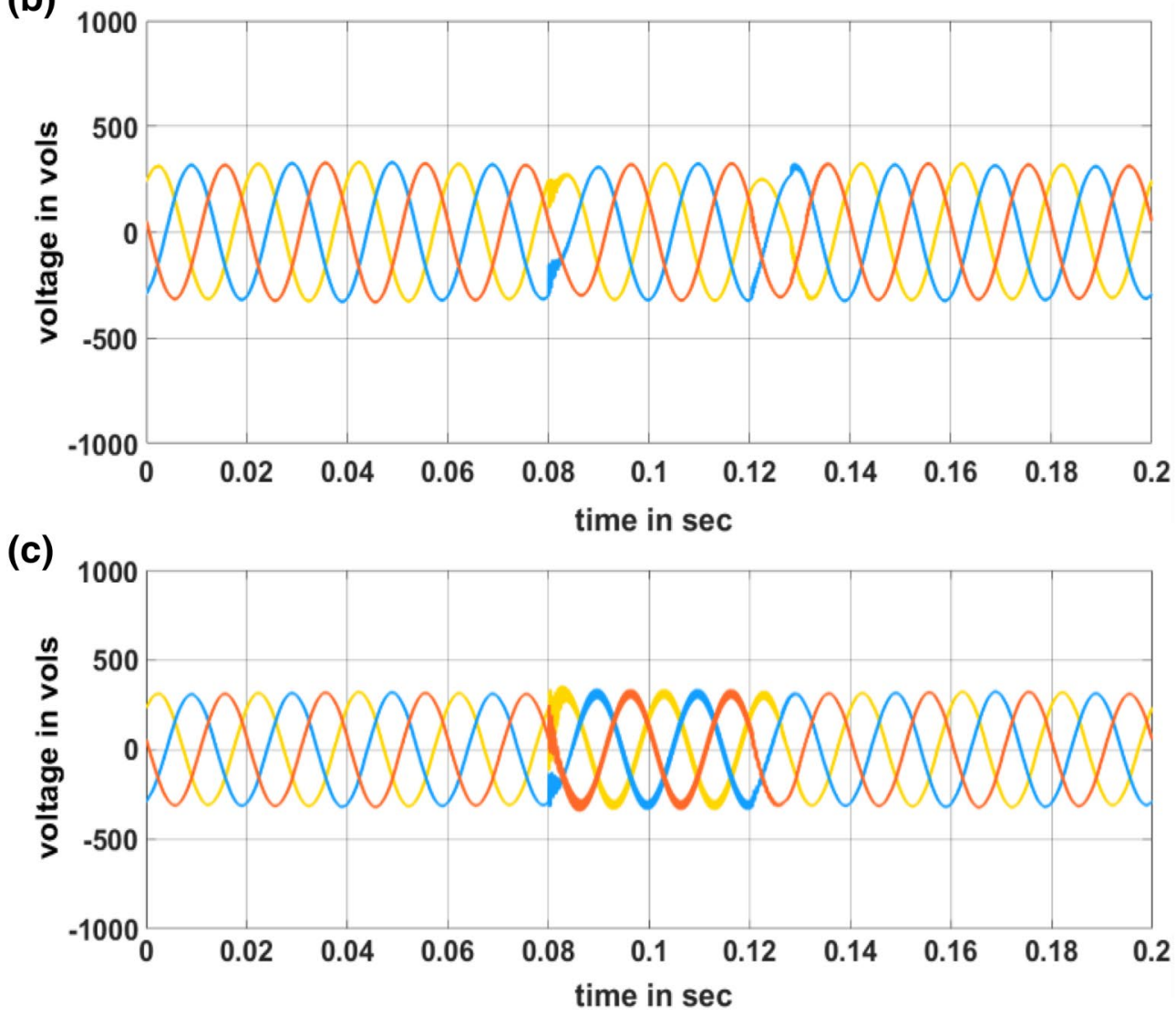

Fig. 9 a Voltages during fault at the loads 1, 2 and 3. b Voltages during fault at the loads 1, 2 and 3 using R-SFCL. c Voltages during fault at the loads 1, 2 and 3 using R-SFCL and SAPF 
Fig. 10 a Voltage harmonics at load-1 using R-SFCL. b Voltage harmonics at load-1 using R-SFCL and SAPF

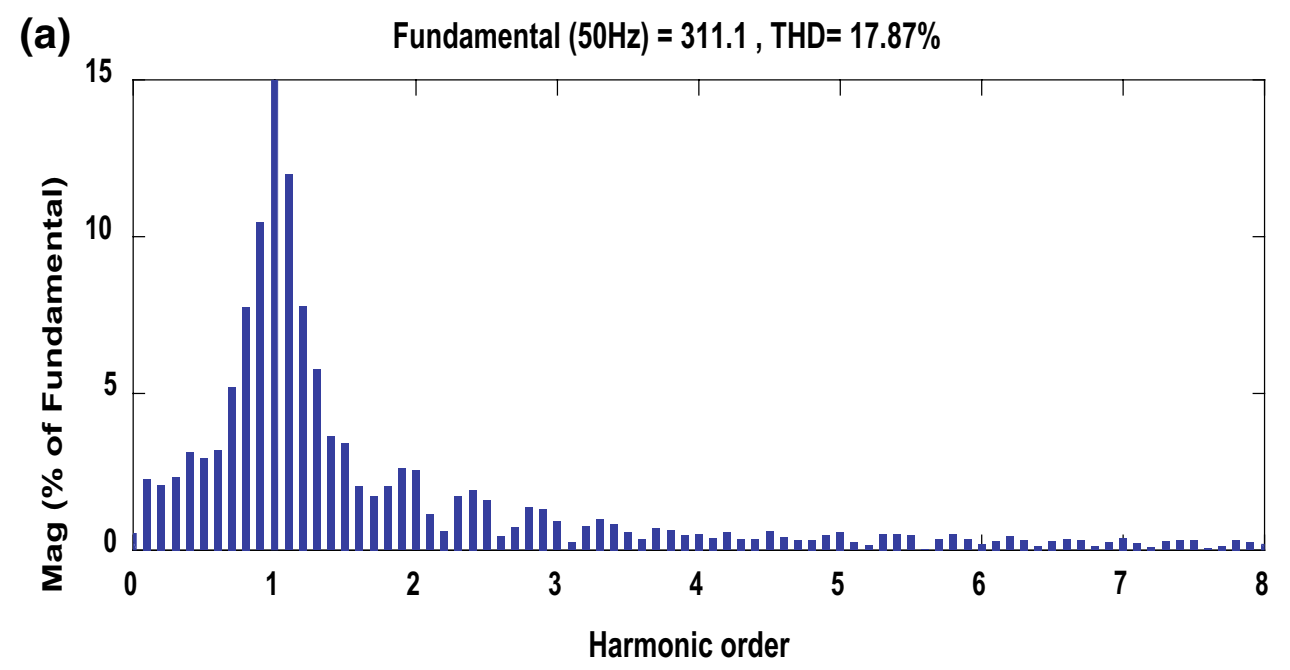

(b)

b) $15 \quad$ Fundamental $(50 \mathrm{~Hz})=310.6, \mathrm{THD}=15.91 \%$

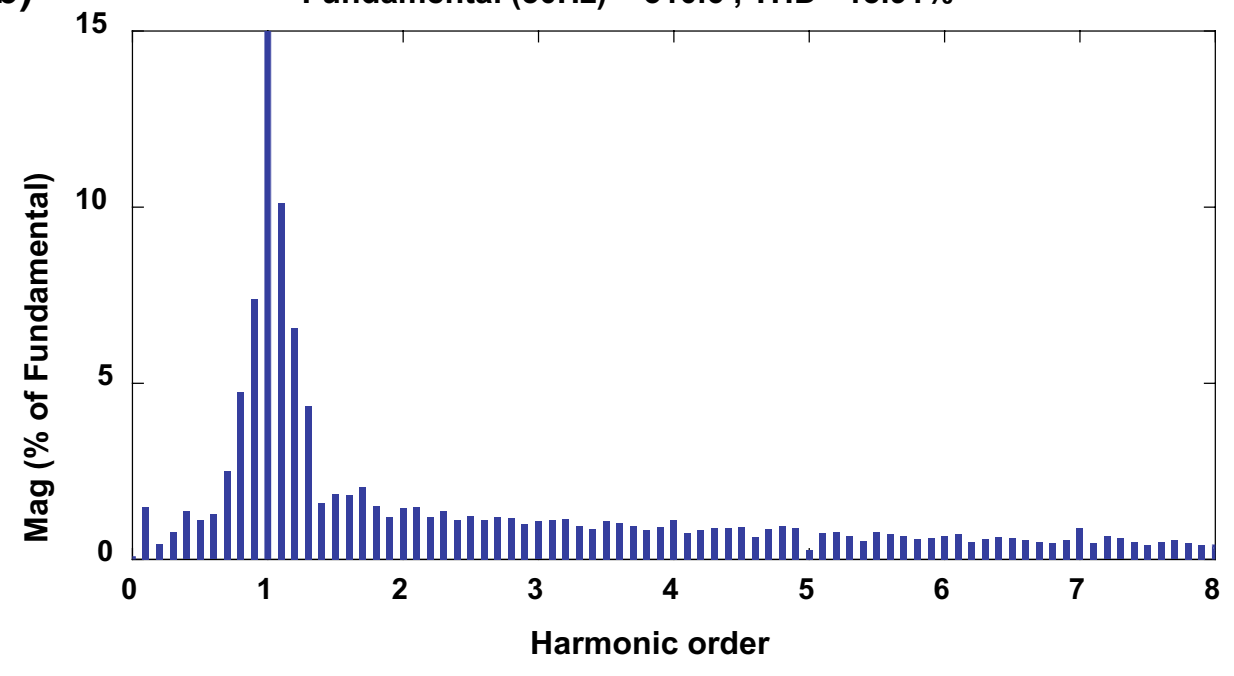


Fig. 11 a Voltage harmonics at load-2 using R-SFCL. b Voltage harmonics at load-2 using R-SFCL and SAPF

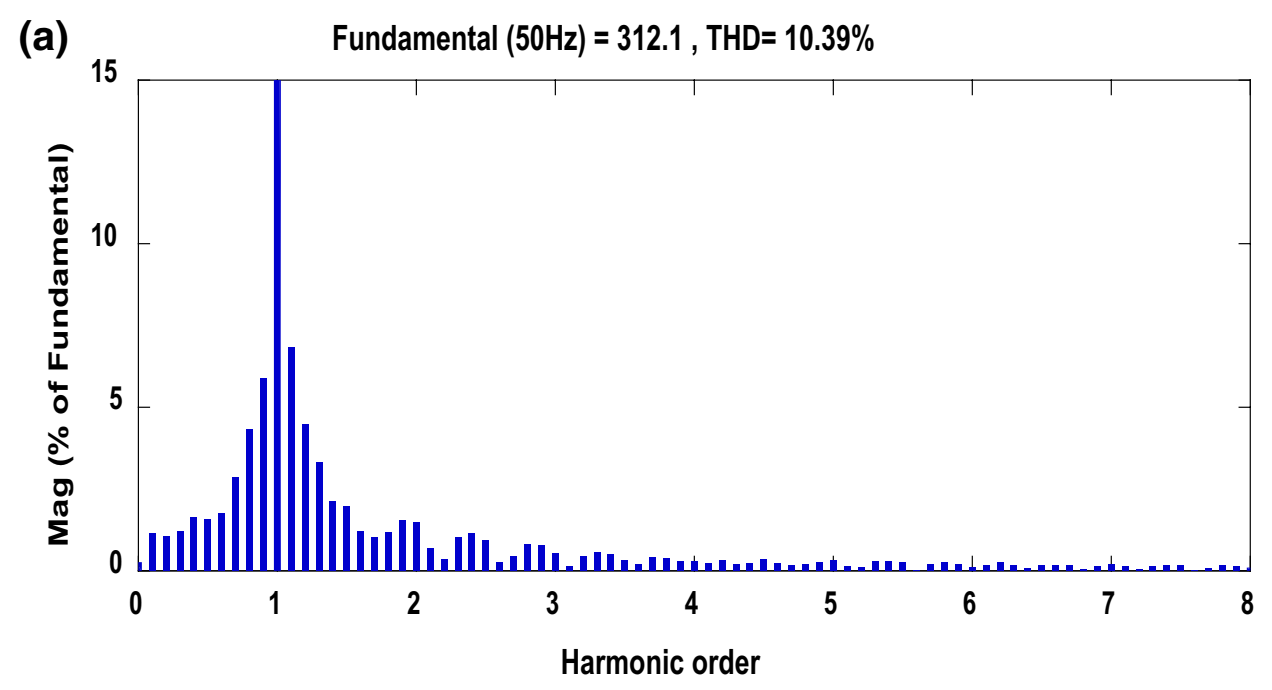

(b)

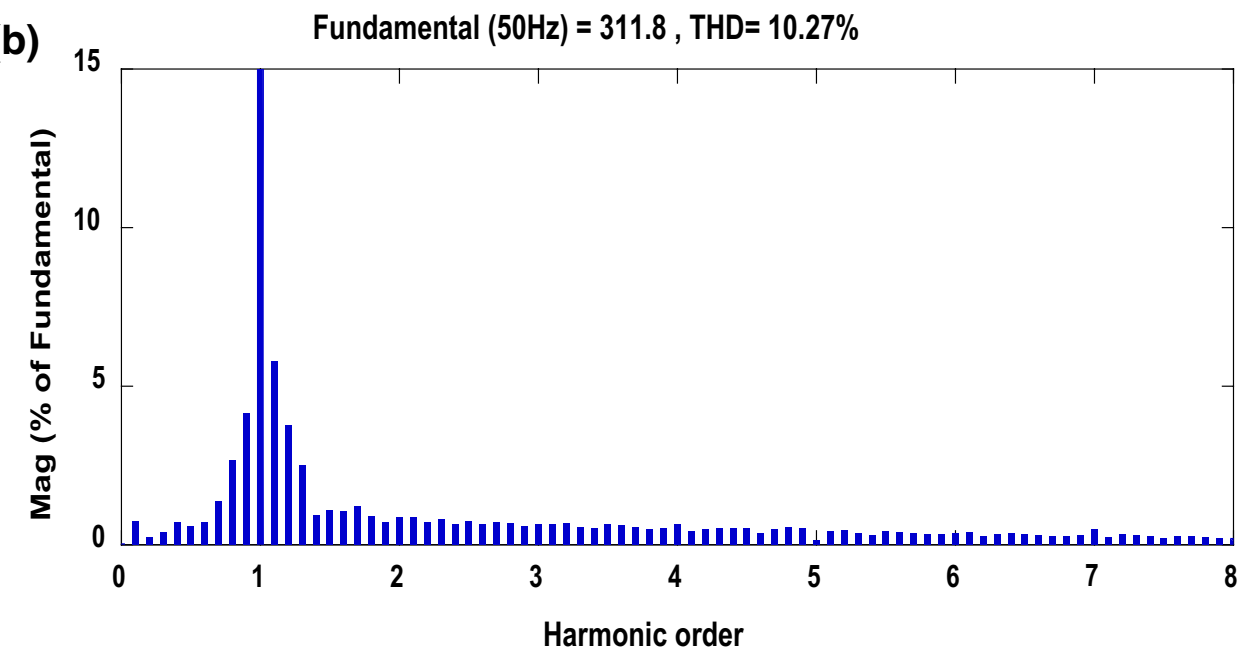

Here by using SAPF, voltage harmonics are reduced from 17.87 to $15.91 \%$ and reactive power is compensated at load-1 then transient stability of microgrid is improved as specified in Fig. 10a, b.

Using SAPF, voltage harmonics is reduced from 10.39 to $10.27 \%$ and reactive power is compensated at load- 2 then transient stability of microgrid is improved as signify in Fig. 11a, b.
Here by using SAPF, voltage harmonics are reduced from 10.30 to $9.49 \%$ and reactive power is compensated at load-3 then transient stability of microgrid is improved as signify in Fig. 12a, b.

From Table 1 harmonics are reduced at three loads with the effective work of Resistive type SFCL and SAPF. 
Fig. 12 a Voltage harmonics at load-3 using R-SFCL. b Voltage harmonics at load-3 using R-SFCL and SAPF

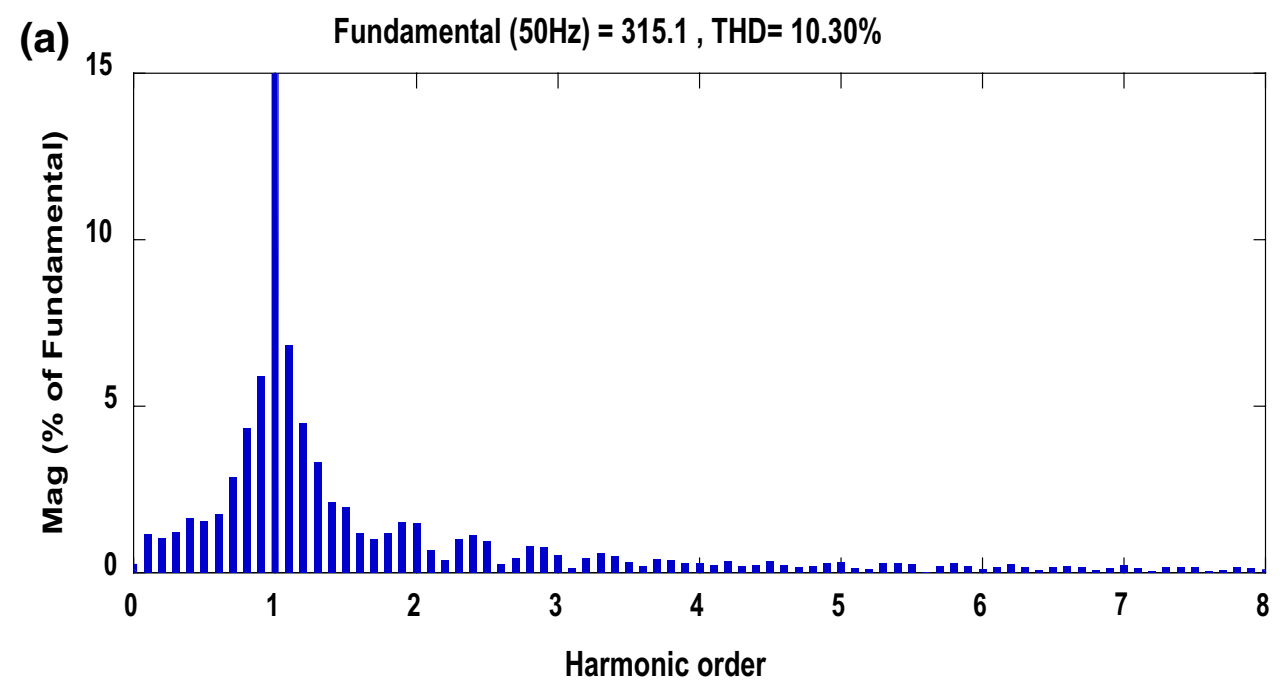

(b)

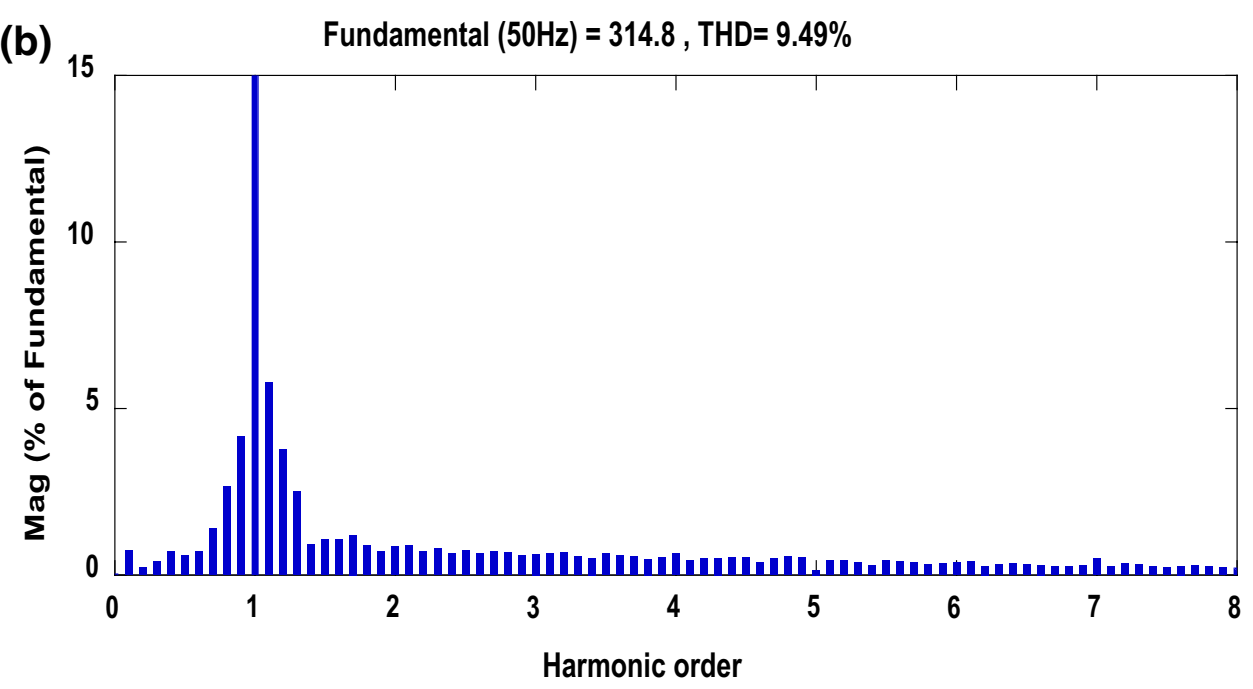

Table 1 Harmonic analysis at different loads

\begin{tabular}{lll}
\hline Loads & THD of R-SFCL (\%) & $\begin{array}{l}\text { THD of } \\
\text { R-SFCL and } \\
\text { SAPF }(\%)\end{array}$ \\
\hline Load-1 & 17.87 & 15.91 \\
Load-2 & 10.39 & 10.27 \\
Load-3 & 10.30 & 09.49 \\
\hline
\end{tabular}

In this proposed system, at the time of fault condition, fault currents were limited and voltage levels was compensated then power transfer capability increased at load-1 $150+\mathrm{J} 25$ (kVA) specified in Fig. 13a-c.

In this planned system, at the time of fault condition, fault currents were limited and voltage levels was 
Fig. 13 a Power during fault at load-1. b Power during fault at load-1 with R-SFCL. c Power during fault at load-1 with R-SFCL and SAPF
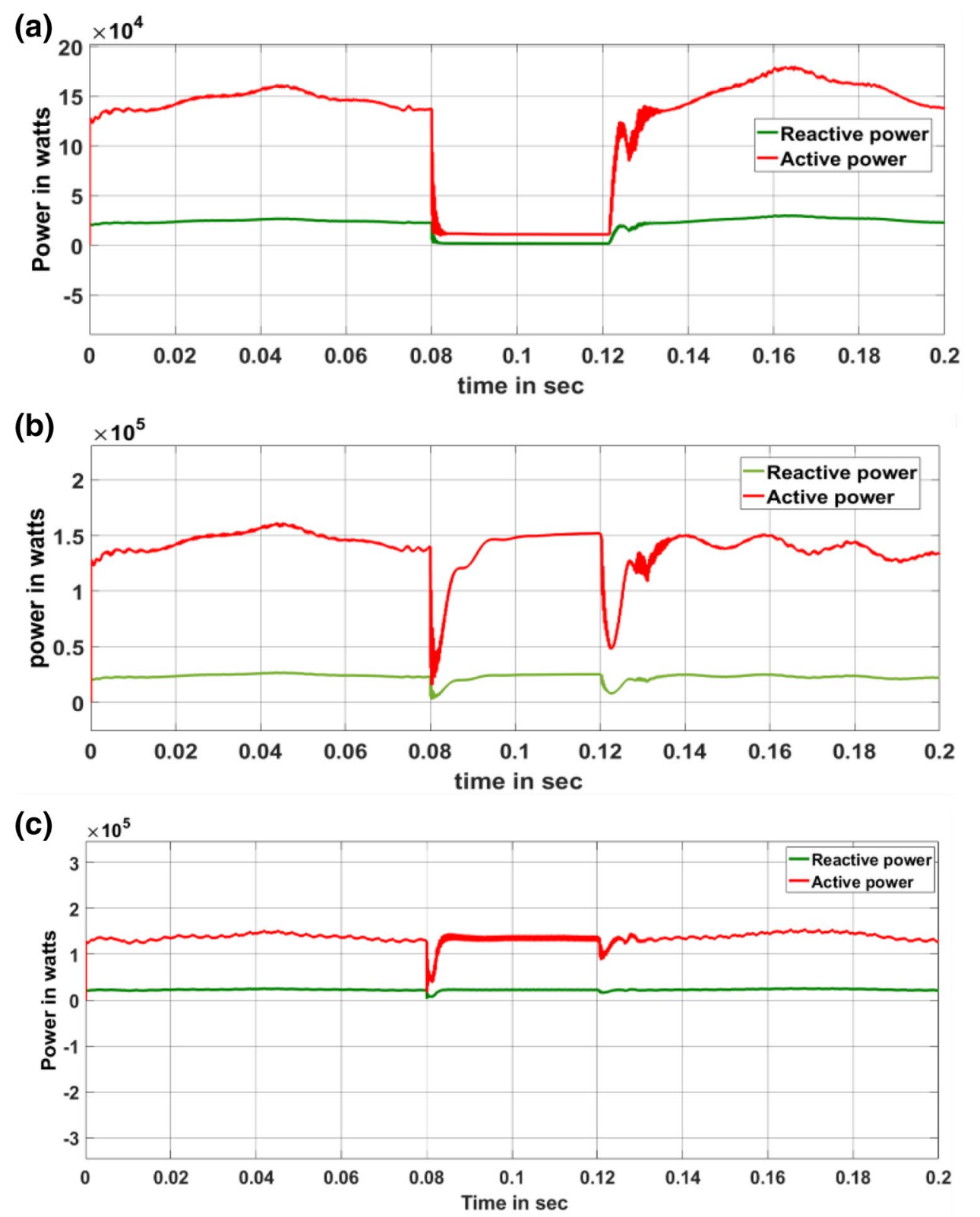

compensated then power transfer capability increased at load-2 $450+$ J30 (kVA) specified in Fig. 14a-c.

In this microgrid system, at the time of fault condition, fault currents were limited and voltage levels was compensated then power transfer capability increased at load-3 $200+$ J20 (kVA) specified in Fig. 15a-c.
In this article, with this proposed work, fault current limiting ratio at wind DG is increased from $42.1 \%$ [7] to $43.87 \%$.

The verification of fault current limiting ratio had been checked at PV power, here the limiting ratio is increased from $36.2 \%$ [7] to $52.41 \%$. 
Fig. 14 a Power during fault at load-2. b Power during fault at load-2 with R-SFCL. c Power during fault at load-2 with R-SFCL and SAPF

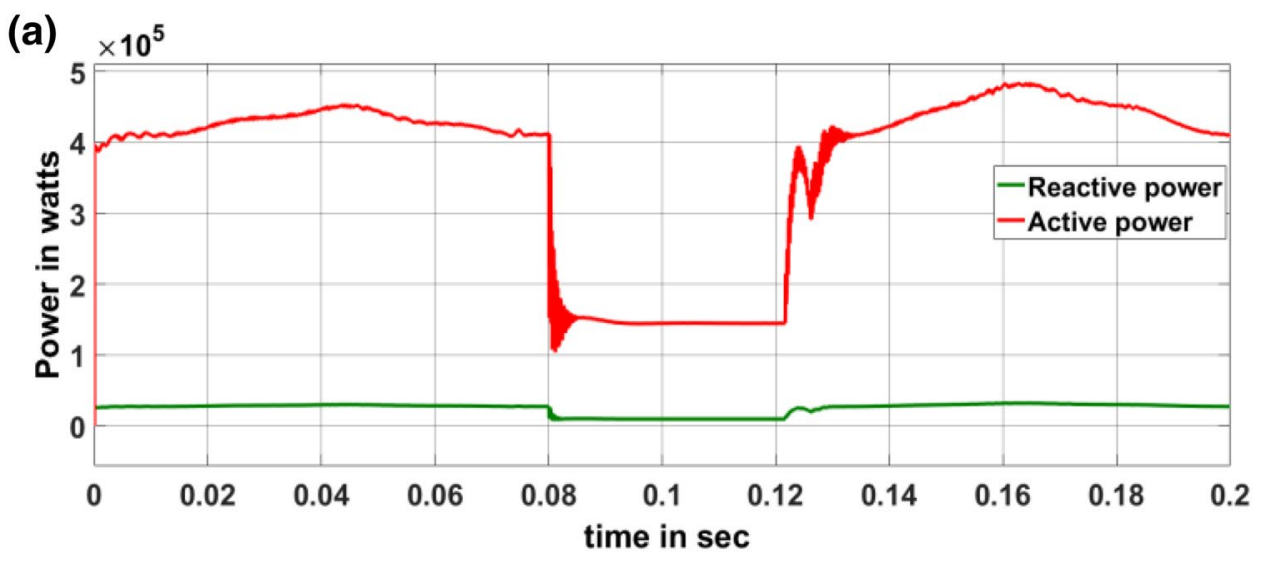

(b)
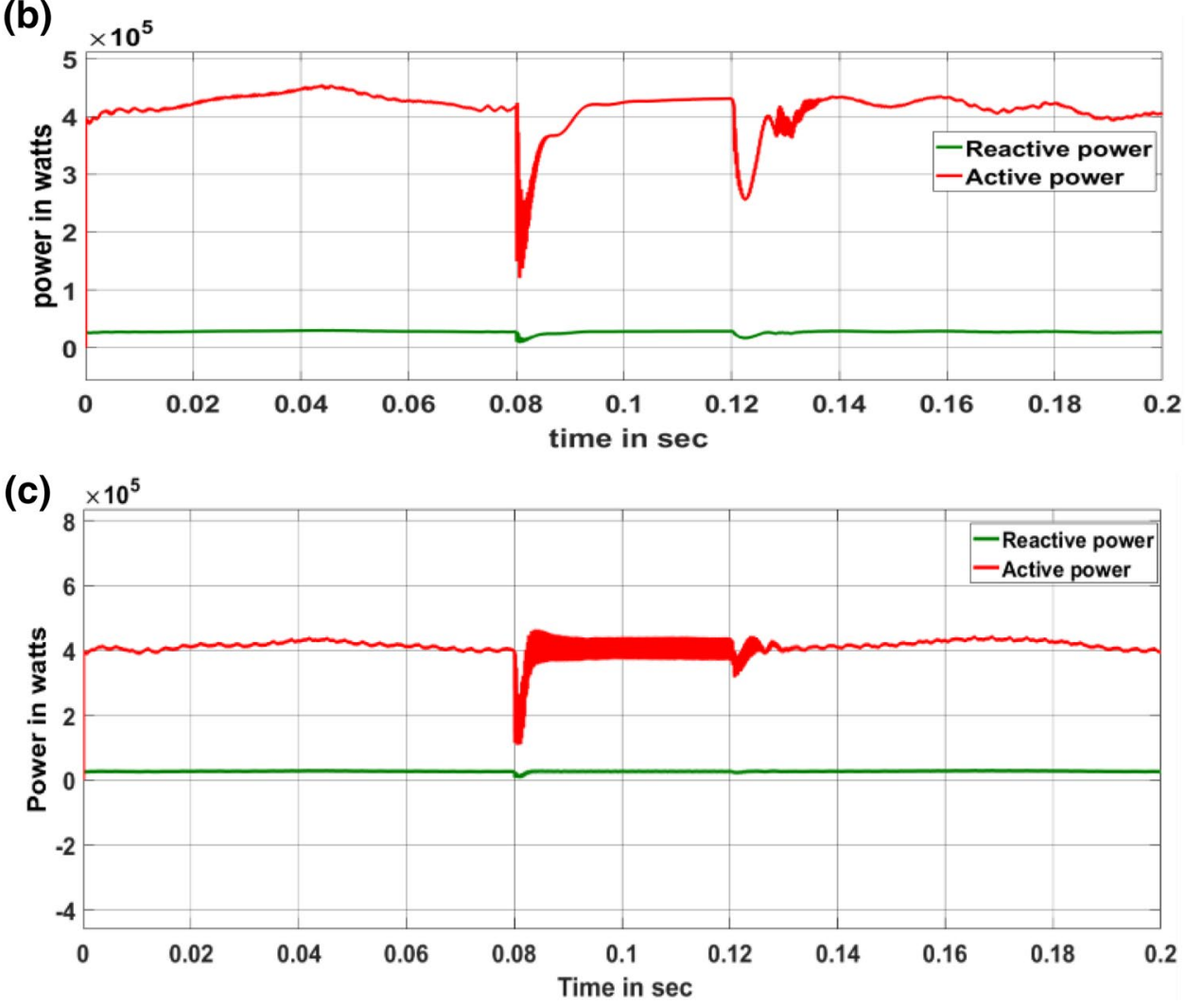
Fig. 15 a Power during fault at load 3. b Power during fault at load-2 with R-SFCL. c Power during fault at load-3 with R-SFCL and SAPF
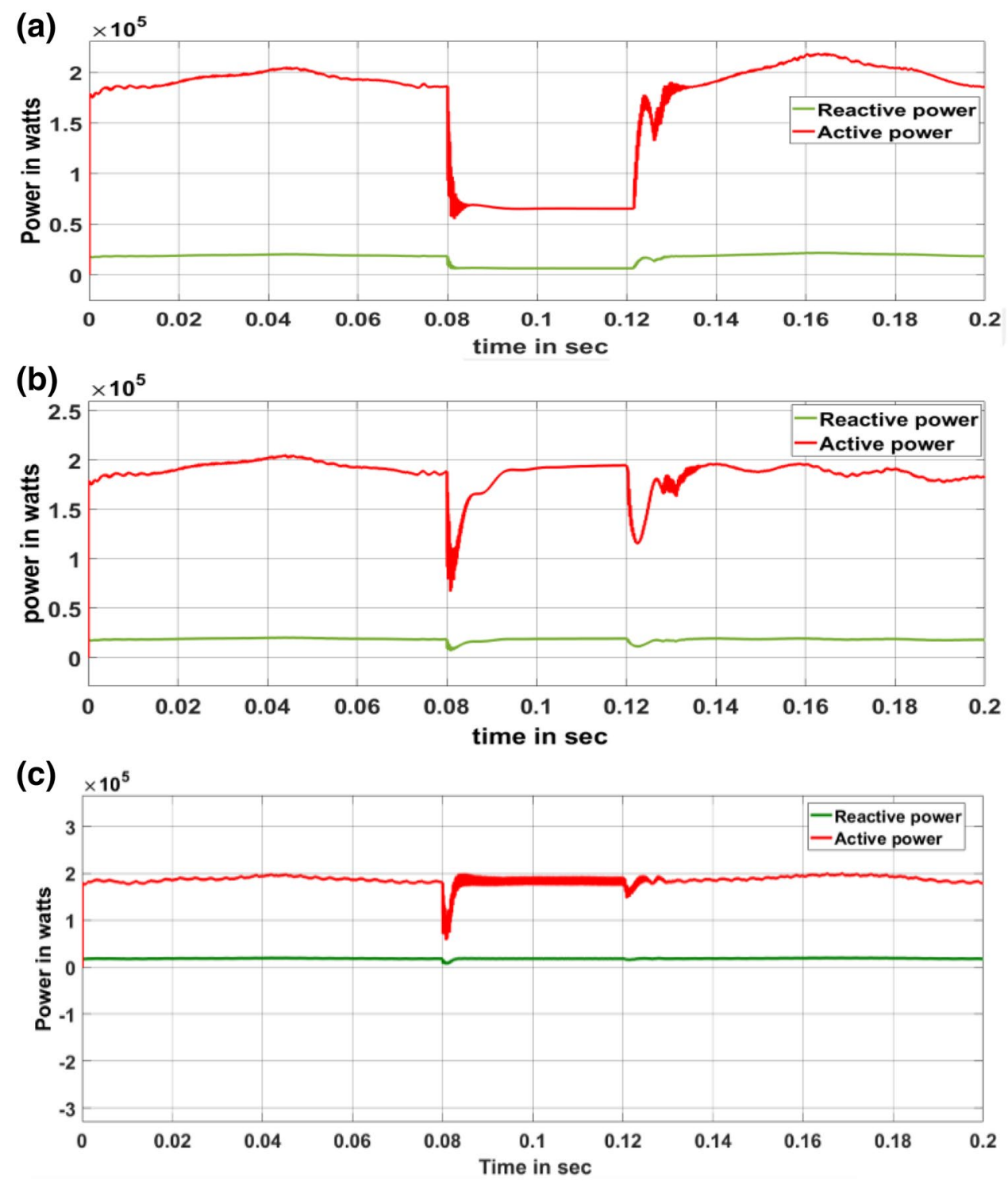

Table 2 Fault current from different locations

\begin{tabular}{lllll}
\hline DG & With fault (A) & $\begin{array}{l}\text { With } \\
\text { fault \& } \\
\text { R-SFCL (A) }\end{array}$ & $\begin{array}{l}\text { With fault, } \\
\text { R-SFCL \& } \\
\text { SAPF (A) }\end{array}$ & $\begin{array}{l}\text { Ratio of fault } \\
\text { current limit- } \\
\text { ing (\%) }\end{array}$ \\
\hline Wind & 1217 & 830 & 683 & 43.87 \\
PV & 1227 & 758 & 586 & 52.41 \\
\hline
\end{tabular}

\section{Conclusions}

This proposed hybrid microgrid system consists of three DG's -wind, solar and fuel cells. Due to the interconnection of the number of DG's, fault currents are produced that which make the microgrid protection a very challenging task. Here R-SFCL has limited the fault currents from 1200 to 830 (A). But R-SFCL has had some disadvantages such as, not compensating for the reactive power and the voltage levels are also not compensated. Because of which SAPF's are used along with R-SFCL. During this instant single-phase RMS voltage is improved from 183 to 235 (volts), fault currents are again limited from 830 to $683(\mathrm{~A})$ as presented in Table 2 and voltage harmonics are reduced as presented in Table 1. Finally, the transient stability has been improved in the microgrids.

\section{Compliance with ethical standard}

Conflict of interest The authors declare that they have no conflict of interests. 


\section{References}

1. Blaabjerg F, Teodorescu R, Timbus AV (2006) Overview of control and grid synchronization for distributed power generation systems. IEEE Trans Ind Electron 53(5):1398-1409

2. Sung C, Park DK, Park J-W, Ko TK (2009) Study on optimal location of a resistive SFCL applied to an electric power grid. IEEE Trans Appl Supercond 19(3):2048-2052

3. Pei $X$, Smith AC (2016) Experimental testing and development of improved modelling for multistrand resistive SFCL. IEEE Trans Appl Supercond 26(4):1-5

4. Rao MUM, Rosalina KM (2018) Microgrid protection by using resistive type superconducting fault current limiter. Model Meas Control A 91(2):89-93

5. Blair SM, Booth CD, Singh NK, Burt GM, Bright CG (2011) Analysis of energy dissipation in resistive superconducting fault-current limiters for optimal power system performance. IEEE Trans Appl Supercond 21(4):3452-3457

6. Rao MUM, Rosalina KM (2017) Transient stability improvement of microgrids by using resistive type SFCL and series active power filters. Eur J Electr Eng 19(3-4):181-195

7. Zheng F, Deng C, Chen L (2015) Transient performance improvement of microgrid by a resistive superconducting fault current limiter. IEEE Trans Appl Supercond 25(3):1-5
8. Lim S-H, Lim S-T (2019) Analysis on coordination of over-current relay using voltage component in a power distribution system with a SFCL. IEEE Trans Appl Supercond 29(5):5603605

9. Chen L, Tian X, Xu Y (2018) Coordination of SMES, SFCL and distributed generation units for micro-grid stability enhancement via wireless communications. special section on advanced energy storage technologies and their applications. IEEE Access 6:36699-36710

10. Lan T, Li Y, Duan X, Xiao Hao (2019) Location and size determination method of SFCLs in multi-terminal VSC-HVDC using iterative current reduction ranking. IET Renew Power Gener 13(11):1927-1937

11. Ainslie MD et al (2009) Superconducting fault current limiter design using parallel-connected YBCO thin films. IEEE Trans Appl Supercond 19(3):1918-1921

12. Ribeiro RE, Barbi I (2006) Harmonic voltage reduction using a series active filter under different load conditions. IEEE Trans Power Electron 21(5):1394-1402

13. Salmerón P, Litrán SP (2010) Improvement of the electric power quality using series active and shunt passive filters. IEEE Trans Power Deliv 25(2):1058-1067

Publisher's Note Springer Nature remains neutral with regard to jurisdictional claims in published maps and institutional affiliations. 